\title{
Augusto Roa Bastos y El trueno entre las hojas
}

1

El poeta: de Garcilaso a García Lorca

No hay entre los escritores jóvenes del Paraguay nadie que iguale o supere a Augusto Roa Bastos. Como artífice del verso y de la prosa, como maestro consumado de los recursos de su oficio, no tiene rival entre los miembros de su generación. Su laboriosa, ininterrumpida e intensa formación literaria; sus largos años de lento aprendizaje en un afán de ensayar su creciente destreza en todos los estilos y géneros literarios; en suma, su infatigable voluntad de perfección y la disciplina que se ha impuesto para lograrla, le han hecho dueño de un idioma poderoso en imágenes, ágil, flexible, rico en colores y en matices, cabalmente adecuado para la pintura del mundo exterior y. para el análisis de complejísimas reacciones psicológicas.

Roa Bastos, sin embargo, como su compatriota Natalicio González, el más brillante escritor de una generación anterior, es un autodidacto. En cierto modo ha sido una circunstancia favorable tanto para Roa como para González el no ser bachilleres ni doctores. Acaso su misma carencia de títulos académicos les llevara a conquistar el puesto de honor que tienen entre los intelectuales de su país, en virtud de un esfuerzo personalísimo, cuyos resultados compensaran con creces las ventajas de la disciplina escolástica. Así evitaron la vana complacencia doctoral - $\tan$ común en el medio-, 
y esa deleznable seguridad que ofrece una presunción de capacidad y de saber, oficializada por un grave documento, a menudo falto de significación efectiva.

Roa Bastos se inició en las letras hace unos veinte años, con la imitación de los grandes poetas españoles del Renacimiento. Allá por 1935, escribe unos sonetos que parecen arrancados de una antología del siglo xvi Su primer maestro es Garcilaso de la Vega.

El extraordinario poder que tiene Roa para el dominio de las más diversas maneras de la lengua literaria, le permite manejar sin esfuerzo el español del Siglo de Oro, como si este adolescente, nacido en el corazón subtropical de la América del Sur, en el segundo decenio del siglo xx, no tuviera otra patria espiritual que la España de Carlos V ni otro reino poético que el neoplatonismo renacentista en una arcadia ideal de eterna primavera. ${ }^{1}$

Sobrino de monseñor Hermenegildo Roa, sacerdote culto y virtuoso, de cultura y gustos clásicos, Roa Bastos hace sus primeras lecturas en la biblioteca de su tío. En los sonetos garcilasianos de la primera época, tañen rabeles rústicos, ruedan arroyos cristalinos por verdes prados y el infalible ruiseñor gorjea en las ramas de árboles añosos.

Es tan melodiosa, no obstante, la versificación del joven poeta y tanto prometen esas melodias de arcaica resonancia, que el anacronismo tiene un encanto refrescante. Roa Bastos no publica sus versos todavía. Los copia, sí, a máquina; los firma con su menuda caligrafía perfectamente legible y los enseña a algunos de sus amigos.

Un día de 1938, siendo a la sazón redactor de El Diario el que escribe estas cuartillas, pidió al poeta una selección de sus versos para publicárselos en un número dominical. Al domingo siguiente aparecieron, llenando toda una plana, varias de las mejores poesías juveniles de Augusto Roa Bastos. Así los lectores asunceños conocieron al joven poeta que, como un lírico Don Quijote metido a pastor, queria resucitar, a orillas del río Paraguay, la edad de oro de la poesía pastoril.

Fué en aquel tiempo cuando apareció en un periódico de Asunción una epístola en verso, exhortando a Roa a cambiar de estilo, 
de temas y de lenguaje. Parodiando amistosamente el léxico y la arcaica sintaxis del joven poeta, el autor de la epístola le decía :

El tu arcaico rimar $y$ tu lenguaje que evocan áureos tiempos y pasados, a la usanza del siglo, son ultraje. Aquesto digo porque mis cuidados nacen del noble afán de ver tu gloria y tus sueños de artista realizados. ¿A qué fablar la que olvidó la historia, lengua de los tan viejos Nemorosos de que ni ratas ya guardan memoria... 2

Aunque no se mencionaba el nombre del poeta aludido, Roa Bastos recogió la alusión y respondió a la epístola con otra, también en verso, y en el más ortodoxo lenguaje renacentista, defendiendo su actitud y justificando su clasicismo. Haciendo profesión de modestia y de desdén por la pasajera moda de los tiempos, el poeta arcaizante declaraba en uno de sus tercetos:

No quiero yo oropel ni quiero honores, que escribo sin cuidarme del presente y del futuro ingrato en sus favores...

Cuando más, su actual garcilasismo sería una etapa útil y necesaria en el proceso de su aprendizaje literario:

... Yo en tanto quiero retrasar mi paso, que no tengo premuras, $y$ más precio probar mi lira al son de Garcilaso que en neo-sensible estilo imitar necio las jerigonzas de las musas nuevas... 3

Pero Roa Bastos no iba a pasar toda su juventud en la arcadia artificial de la Edad de Oro, estando llamado a ser - como lo estaba-, uno de los renovadores de la poesía en el Paraguay. $\mathrm{Y}$ un día, sin más transición que unas lecturas entusiastas de Valle Inclán y Juan Ramón Jiménez, descubre a Federico García Lorca. $Y$ es entonces cuando se produce un cambio radical en su estilo y en su sensibilidad. Los pastores tañedores de rabeles de sus poemas garcilasianos, se agitanan al influjo del romancero lorquiano, $y$, aclimatados 
al ambiente hispano-guarani, comienzan a danzar bajo los cielos tibios del Paraguay.

La gitana Preciosa, por ejemplo, ahora tiene sobresaltos eróticos no ya en un sendero de "cristales y laureles" sino en un paisaje de guayabos y cocoteros bajo el sol ardiente de una siesta paraguaya.

$$
\begin{aligned}
& \text { La mano tibia del viento } \\
& \text { derrama tu cabellera } \\
& \text { como un ungüento de sombras } \\
& \text { sobre tu espalda morena, } \\
& \text { y en tu dormida epidermis } \\
& \text { hinca sus dientes de seda. } \\
& \text { La mano del viento niño } \\
& \text { que con los rosales juega, } \\
& \text { los dientes del viento-fauno } \\
& \text { que muerden las azucenas...4 }
\end{aligned}
$$

Como se ve, el viento de este romance de Roa sopla desde las páginas del Romancero gitano; es el mismo viento de "Preciosa y el aire", aquel que es

sátiro de estrellas bajas

con sus lenguas relucientes...

Bajo el influjo de Lorca el endecasílabo garcilasiano se quiebra ahora en las manos de Roa, y, de entre ellas se le escapan versos breves, inspirados por esa poesía andaluza que aparece entre 1920 y 1930:

$$
\text { Era un muchacho rubio. }
$$

Triunfo.

Esqueleto amarillo

es ahora en los campos.

Gusanos.

Y la madre, a los lejos

llorando...5

O esta suerte de romancillo muy nuevo y muy viejo:

-Hijo, ¿a dónde vas?

-A coger naranjas

allá, junto al río. 
-Ven, ponte primero

tu casco de acero.

-Madre, que no quiero.

Madre, yo me río.

Noche.

En vez de estrellas

mil tábanos negros.

Cuando a la mañana

la madre fué al río

con voz amarilla

llamando a su niño,

vió que las naranjas

se iban por el río,

y entre las naranjas, la rubia cabeza

del niño...6

García Lorca le abre a Roa Bastos la puerta de la nueva literatura. Una vez dueño de todo el arsenal poético de Lorca; de toda esa imaginería onírica y alucinante, de todos los nuevos recursos retóricos, tales como le fueron accesibles en los volúmenes de las obras lorquianas publicados en aquel tiempo por la editorial Losada de Buenos Aires, Roa Bastos renuncia para siempre a sus predilecciones clásicas y se consagra a leer y a imitar con entusiasmo a todos los poetas nuevos. Su antiguo anacronismo literario se trueca ahora en un fanático fervor por lo actual, por lo novísimo. Ha terminado, con su época clásica, su casticismo hispanista arcaizante. Ahora estudia a infinitos escritores en traducción, tales como el alemán Rilke, el checo Kafka, el irlandés Joyce. Halla su catecismo literario en André Breton, en Apollinaire, en Cocteau, en Marinetti y se desentiende de toda la literatura española que no pertenezca a la nueva tónica.

En su cultura literaria hay una gran laguna representada por un salto de los siglos XVI y xvir al siglo xx. Apenas tiene noticias, por ejemplo, de la ingente literatura novelística del siglo xIX, de los Stendhal, de los Flaubert, de los Eça, de los Galdós y de los grandes rusos. Desconoce a los poetas románticos y a los post-románticos. Pero esto a él no le importa. Por el momento le es necesario ponerse al dia, ser un poeta nuevo, revolucionario. $\mathrm{He}$ aquí lo que ahora le es urgente. Lo demás vendrá después. 
En este tiempo el joven poeta conoce a dos colegas también nuevos: el malogrado Hérib Campos Cervera y la escritora hispanoparaguaya Josefina Pla.

Campos Cervera pertenece a una generación inmediatamente anterior, pero es también un discípulo de Lorca y un ferviente admirador de Neruda. Tiene además vocación filosófica, y profesa un existencialismo más poético que estrictamente doctrinario. Ha leído algo de Kierkegaard, ve un maestro en Unamuno, se interesa en Heidegger y lee a Rilke con fervor. En sus poemas se trasunta una fuerte influencia de Lorca, de Neruda y de Alberti. Campos Cervera vive $e n$ poeta ; lleva una existencia llena de emociones fuertes, de "angustia", de lecturas continuas, de tertulias literarias. Es un bohemio que ha sabido conciliar el ensueño y el orden, el superrealismo y la inteligibilidad. Reside con su esposa en una casa alhajada con buen gusto, siempre limpia, ordenada, donde no hay un libro fuera de lugar ni una colilla amanecida en los ceniceros.

Josefina Pla, dueña de una prosa viril y de un estilo poético muy personal, es también una apasionada de lo nuevo. Lo nuevo, en ella, sin embargo, parece algo nacido de su ser, surgido de una experiencia genuina, entrañable y dolorosa. $\mathrm{Ni}$ imita ni adapta. Las influencias, en su verso $y$ en su prosa, parecen coincidencias. La nueva literatura no ha venido a ella como una moda que es preciso adoptar, sino que ella la ha hecho y la hace a la par que los otros escritores de vanguardia.

Pronto Roa Bastos, Campos Cervera y Josefina Pla integran un reducido cenáculo literario al que se adhieren, bien que en calidad de discipulos, otros jóvenes escritores.

Campos Cervera y Josefina Pla hacen una literatura sombria y pesimista. Vivir, para Campos, no es otra cosa que "ir muriendo". Le obsesiona la idea del anonadamiento ineluctable de su individualidad y del de los seres y las cosas entre los que, día tras día, el poeta, avanza hacia la muerte. ${ }^{7}$

En Josefina Pla el tema de la muerte se entrelaza con el del amor, el del amor como pasión trágica, lacerada de amargura y desesperación.

La intimidad de estos dos poetas de la muerte y de la desolación espiritual, produce en Roa una impresión profunda. Aunque temperamentalmente muy distinto de sus dos amigos - más avanzados 
en la vida y lastimados por una experiencia amarga de que él aún carece-, Roa asume a su vez una actitud pesimista que, acaso mera pose literaria en un principio, constituirá más tarde una genuina postura espiritual ante el mundo y la existencia.

El superrealismo es en aquel entonces no ya una moda que el trio pretende imponer, sino una verdadera religión literaria. Una religión politeista, sí, de muchos dioses, pero cuidadosamente elegidos para el culto. Son los dioses nuevos, algunos de los cuales fueron ya citados arriba, y a cuya lista hay que agregar otros muchos, como el inglés Charles Morgan, el francés Alain Fournier y los norteamericanos O'Neill y Faulkner. En la capilla hay muchos altares, pero hay también un Index donde todos los pasatistas están "prontuariados» y excluídos.

Esto acontece en todos los movimientos literarios de renovación. Las revoluciones -cualesquiera que éstas sean-, se efectúan en virtud de apasionadas intransigencias y de limitaciones ideológicas, al par que de rígidos exclusivismos de la sensibilidad. De aquí que sea raro el caso del revolucionario capaz de apreciar, con amplitud de miras, sin prejuicios ni prevenciones, la dosis positiva de verdad o de belleza contenida en las obras del pensamiento y del arte. E1 hombre unbiased lo más que puede hacer es aceptar la revolución, no iniciarla.

E1 mérito de Roa Bastos, Campos Cervera y Josefina Pla, consiste en haber desempeñado su papel renovador con abnegación y entusiasmo, a despecho de una aplastadora dictadura, cuando la vida intelectual de Asunción parecía volver a los tiempo del doctor Francia. Sólo estas tres figuras señeras, unidas en la soledad espiritual de una ciudad vigilada a toda hora por espías policíacos, se consagró a suscitar en aquel ambiente cargado de intrigas y temores, un interés creciente por las nuevas tendencias literarias.

Roa Bastos escribe en esta época infinitos versos que, con la misma pulcritud de siempre, copia a máquina y firma con su apretada caligrafía, en las oficinas del periódico El País, de que ahora es redactor. Tiene Roa poemas en todos los bolsillos - -poemas superrealistas, oscuros, ininteligibles-, entre los cuales brilla a veces como un arcoiris en las tinieblas oníricas, alguna estrofa de sorprendente belleza. 
En las tertulias reunidas en los lentos atardeceres de Asunción - en la Casa América, en las librerías Salazar y Universal, o en las esquinas de la calle Palmas-, Roa, entre sus amigos, es el que más habla porque es también el que más lee, el que más aprende, el que más se entusiasma. $\mathrm{Y}$ alli, con Campos Cervera, con Josefina Pla, con Facundo Recalde, con Elvio Romero, con los hermanos Moreno González, Roa menciona un tema que acaba de desarrollar en algunos versos recientes; comunica las emociones que se lo inspiraton, habla de nuevos desarrollos, traza proyectos de otros poemas, o de cuentos, o de piezas de teatro - porque Roa, además, es cuentista y dramaturgo-. Y entonces saca de uno de los bolsillos un fajo de cuartillas: versos largos, versos cortos, versos con rima o sin rima; buenos unos, malos otros, pero todos ellos un verdadero alarde de virtuosismo poético. Los poemas pasan de mano en mano entre los interlocutores, los cuales los leen rápidamente - porque saben que pronto vendrán otros muchos más-, y todos tienen un comentario o una pregunta a la que Roa contesta con notable precisión de conceptos y riqueza de vocabulario. $Y$ entonces Roa sigue hurgando en los otros bolsillos, y nuevos poemas surgen de aquí y de allá, hasta que sus amigos se quedan finalmente como sumergidos en el flúido espirituoso de una incontenible inundación poética.

Roa Bastos es un hombre de treinta y seis años de edad, más bien bajo que alto, de negros cabellos abundantes, peinados con esmero; de tez morena y pálida, grandes ojos melancólicos, nariz también grande y sólida, y unas manos pequeñas, sumamente expresivas, que constituyen un ingrediente esencial de su elocuencia, y a las que mueve sin cesar, con ritmo acelerado, como si quisiera redondear con ellas, plásticamente, las ideas que expone con voz cálida y nasal al mismo tiempo.

\section{La visión del Paraguay}

A raíz de la guerra civil de 1947 Roa Bastos y Campos Cervera tuvieron que expatriarse y buscar asilo en la Argentina. En Buenos 
Aires Campos Cervera publicó su primer y último libro, Ceniza redimida, en que reunió lo mejor de su poesía. $\mathrm{Y}$ tras algunos años de doloroso destierro, murió triste y nostálgico en la gran ciudad extranjera, dejando tras sí una valiosa obra inédita, precisamente cuando el poeta descubría en sí aspectos antes insospechados de su vocación literaria.

Roa Bastos, por otra parte, parecía haber perdido en el destierro la inspiración y la fecundidad. Al menos, tal cosa podría suponerse desde la distancia. Pero el poeta, en verdad, seguía escribiendo y estudiando tanto como se lo permitía su difícil condición de expatriado. Su afán era perfeccionar cada vez más su técnica, hacer de la expresión escrita algo similar a la expresión pictórica, agilitar al máximo aquella su pluma tan diestra ya tanto en el verso como en la prosa. Quería que el idioma fuera en sus manos un instrumento dócil, con múltiples registros, para modular en él todos los matices del sentimiento y dar voz a todos los tonos de la pasión.

Roa es un gran lector, no sólo porque lee mucho sino porque sabe leer. Cuando un libro le entusiasma, ya no se separa de él hasta haberle sorbido los últimos jugos. De este modo capta y atesora en su mente las ideas centrales de aquél, con el ropaje de que las vistió su autor; incorpora a su fantasía las imágenes que más le impresionaron, y estudia y analiza a fondo esa mecánica sutil en virtud de la cual se preparan y verifican los más complejos efectos retóricos.

Por fin, en 1953, rompiendo un largo silencio, Roa publica en la Editorial Losada de Buenos Aires un volumen con el título $E l$ trueno entre las hojas, fruto de largos esfuerzos de perfeccionamiento literario. ¿Poesía superrealista? ¿Una nueva evolución de lo novísimo? No: el volumen es un conjunto de cuentos breves y trágicos. Los personajes son paraguayos y el escenario de todos ellos es el Paraguay.

El título del libro es el mismo que el del último de los cuentos. Al comienzo de la obra, y a manera de introducción, Roa nos explica el sentido del nombre sugestivo puesto a la totalidad de sus narraciones. Según una leyenda aborigen:

El trueno cae y se queda entre las hojas. Los animales comen las hojas y se ponen violentos. Los hombres comen los animales y se 
ponen violentos. La tierra se come a los hombres y empieza a rugir como el trueno...8

$\mathrm{Y}$ el Paraguay que Roa nos pinta es, en verdad, una tierra que ha devorado el poder cósmico del trueno; una tierra que vive en la violencia, en la injusticia, en la explotación. E1 Paraguay que ve Roa, el que él ha descubierto dolorosamente desde la perspectiva del destierro es, por un lado, un país de cuarteladas continuas, de caciques y militarotes mandones, de negreros ambiciosos y crueles. $\mathrm{Y}$ es, por otro lado, el país del campesino desvalido y explotado, víctima de la violencia ambiente, de la avaricia y de la injusticia organizadas como sistema.

Lejos están sus páginas amargas de las de la literatura paraguaya anterior, literatura que constituye un canto glorificador de los héroes de la epopeya nacional, de los que lucharon en Curupaity y en Humaitá, en Rubio- $\tilde{N} u$ y en Cerro Corá. (En el Paraguay es raro el escritor que se atreva a decir que el pais no representa, en rigor, el mejor de los mundos posibles. Todavía creemos que glorificar al mariscal López o reivindicar la memoria del doctor Francia es tarea más patriótica que elaborar un programa constructivo de regeneración nacional a la luz de una crítica severa de los males que retardan* indefinidamente la evolución política, social, económica y cultural del país. Nuestros escritores prefieren exaltar las dictaduras del pasado, sin caer en la cuenta de que así justifican las del presente y preparan las del futuro).

El patriotismo de Roa es, pues, excepcional; es un patriotismo amargo y violento, exacerbado por la injusticia, indignado por la explotación de los débiles, enfurecido por el retraso de su pueblo.

Se diría que también en este escritor, ayer poeta de una arcadia eternamente primaveral, vibrara algo de ese violento poder cósmico que, según la leyenda aborigen, cae del cielo, se contagia a la flora y a la fauna, pasa luego a las almas de los hombres y penetra al fin en las entrañas de la tierra para sacudirla con su furia.

En este aspecto de su obra, Roa tiene como precursores en el Paraguay a Rafael Barret y a Julio Correa. ${ }^{9}$

El trueno entre las hojas es un libro apasionado y terrible. El lector pasa de un cuento a otro como librándose de una pesadilla para caer en otra. Roa es cruel porque quiere abolir la crueldad y la injusticia, la tiranía y la explotación. 
El mensaje de nuestro escritor parece ser este:

Entre los grandes ríos que limitan el área del Paraguay, se extiende el reino de la naturaleza. No hay nada más que naturaleza entre esos límites de agua azul en fuga hacia el océano...

Porque se diría que Roa hubiese buscado en su patria las huellas del soplo del Espíritu y que sólo hallara en los pueblos, en las ciudades y en los campos el sacudimiento de ese poder elemental del trueno.

El Espíritu es una aspiración trascendente de justicia, de verdad y de belleza en el gobierno y en la actividad y conducta de las sociedades humanas. Doquiera él sopla, la fuerza bruta de los instintos y pasiones que pugnan por afirmar el dominio de su ciega elementalidad, cede en violencia; un equilibrio de fuerzas antagónicas se establece; comienza el imperio de los valores superiores, y se inicia una etapa de alta cultura. En un sentido estricto, con la aparición del espíritu en su lucha contra la naturaleza, comienza la progresiva desanimalización del hombre, y, con ella, la aurora de la libertad, es decir, el verdadero despertar de la Historia.

Se diría, pues, que El trueno entre las hojas tuviese una honda significación simbólica que se nos aclara a la luz de esta interpretación. Sería el libro así una amarga visión de la humanidad paraguaya concebida como pura naturaleza; una suerte de epopeya de los instintos y pasiones bestiales del hombre aun no transfigurados por el soplo dignificador del espíritu.

Por otra parte, el lector que busque en este libro un conjunto de paisajes del Paraguay - tierra cálida y fecunda, de campos verdes, selvas tropicales, anchos ríos y cielos siempre azules-, sufrirá un total desencanto. No hay paisajes en El trueno entre las hojas. El libro no es una visión estética de la tierra, sino una airada protesta que se expresa en el sufrimiento resentido, impotente y sin remedio, de seres de ficción flagelados por un destino trágico.

El apasionado afán de redención que anima a la obra toda $\mathrm{y}$ que, desde el punto de vista ético honra a su autor, desde el punto de vista estético constituye un factor negativo. El libro hubiera constituído un logro artístico muy superior si en él Roa hubiese integrado la visión del sufrimiento del hombre y la visión estética del paisaje. Los males que el escritor pugna por extirpar con su 
palabra ardiente deberían estar más entrañablemente localizados, adscriptos a un paisaje estéticamente vivido e interpretado.

Cuando un artista tiende a subordinar el arte a un propósito no artístico, por noble que este último sea, el arte se venga del artista porque el fin perseguido se logra a medias o se malogra del todo. La verdad que el artista nos transmite, tiene por fuerza que ser, ante todo, una verdad estética. El artista que quiere interpretar, para redimirlo, el dolor del semejante - del semejante que vive en la tierra y de la tierra-, tiene que darnos una visión total del dualismo inescapable del drama en que la vida de aquél consiste.

A El trueno entre las hojas le falta sabor a tierra. En este libro está el hombre a solas consigo mismo o con los demás. La visión del paisaje circundante, cuando más, es vaga, o parcial o inadecuada. A veces es la de un paisaje convencional más o menos propio de cualquier país de clima similar.

Sirva de ejemplo la siguiente descripción:

\begin{abstract}
Otra vez un venadito llegó saltando por entre el pajonal hasta muy cerca de la casa. Cuando Margaret corrió hacia él llamándolo, huyó trémulo y flexible, dejando en los ojos celestes de la alemanita un regusto de ternura salvaje, como si hubiera visto saitar por el campo un corazón de hierba dorada, el fugitivo corazón de la selva. Otra vez fué un guacamayo de irisado cuerpo granate, de pecho índigo y verde, alas azules, larga cola roja y azul y ganchudo pico de cuerno; un arcoiris de pluma y ronco graznido posado en la rama de un timbó... (p. 17)
\end{abstract}

Esto es muy bonito, sin duda, aunque más nos recuerde una película de Walt Disney que otra cosa. Además, el estilo de esta descripción es, diríamos, barroco. Ahora bien: el estilo que requiere el paisaje paraguayo es, por el contrario, uno totalmente distinto, porque impone una serena simplicidad. El Greco no sería el paisajista ideal del campo paraguayo, el cual se desarrolla mansamente tranquilo ante los ojos, con sus cielos azules, sus llanuras verdes, su tierra roja, sus suaves colinas. Es un paisaje, en fin, en que predomina un sentimiento telúrico de fecunda y cálida tranquilidad; en que la naturaleza, generosa, no lo es en demasia; en que la tierra, llana u ondulada, desconoce el perfil dramático de las montañas; en que las selvas, verdes y aromadas, no tienen nada de terrible. 
Roa debería hacer en literatura lo que ya han empezado a hacer en pintura un Samudio, un Holdenjara, un Delgado-Rodas y, más recientemente, un Laterza.

Se diría que nuestro escritor no se hubiese confrontado nunca con el paisaje paraguayo a fin de captarle sus esencias estéticas.

Por el contrario, otra cosa muy distinta sucede con la ciudad, o, mejor dicho, con Asunción. Roa sabe pintarnos la ciudad en que ha nacido y vivido los mejores años de su vida. Esto se ve, por ejemplo, en la admirable descripción de un suburbio asunceño en el cuento "Galopa en dos tiempos".

En este notable relato - notable por la vida que en él palpita, por la impresión de realidad auténtica que nos ofrece y por la precisión de las imágenes-, la Asunción suburbana aparece como una entidad viva que se transforma, que avanza hacia el campo y lo conquista imponiéndole una forma de existencia sórdida y bullanguera. $\mathrm{Y}$ esta visión de los bajos fondos de la ciudad nos la da Roa con la historia de un hombre maduro que retorna al suburbio de sus mocedades después de quince años de ausencia.

Con su plebeyismo acre y ruidoso, en las horas nocturnas del jolgorio barato, el arrabal se hace patente a los ojos del lector como una sucesión de imágenes coloreadas, vivientes, proyectadas sobre una pantalla cinematográfica. En la divisoria de la ciudad y el campo, ve desarrollarse un anónimo drama de amor sumiso por un lado y de frío egoísmo calculador, por otro: un hombre conoce a una muchacha a la que seduce durante la fiesta de arrabal o galopa. Además del habilísimo diseño de los caracteres, nos admira, por la maestría de la evocación, la presencia casi tangible del contorno físico. Aquí el ser humano y su contorno están pintados con igual deleitación estética.

La algarabía del jolgorio adquiere una realidad alucinante. Las escenas se suceden en un tumulto de ruidos, colores, olores, todo esto integrado y armonizado en una rica variedad de sensaciones que complementan la visión cinemática de la galopa. El escritor nos convierte, por decirlo así, en testigos presenciales del episodio arrabalero.

En este relato, entre parẻntesis, la finalidad puramente artística es independiente de todo propósito no estético. Gracias a ello, una gran ráfaga de agria poesía nos envuelve, $\mathrm{y}$, arrancándonos del 
mundo real en que nos hallamos, nos traslada, mágicamente, al lugar de la narración:

El bullicio se fué apagando. La luz también. Era ahora un caminito sinuoso entre los yuyos. Ya se podía sentir la estridulación finita de los grillos, ardiendo en la oscuridad. Tenues hilos de plata sobre el rumor lejano. La noche misma se había puesto de pronto más oscura. Iban caminando entre los mangos. Ni las estrellas se veian. Solamente el denso, el adormecedor perfume de las piñas y los mangos del potrero avanzaba hacia ellos. El olor de la tierra empapada de rocío... (p. 101)

¡El olor de la tierra! ¡ El sabor de la tierra! Esto es precisamente lo que falta en muchos otros cuentos.

Pero no en todos ellos. Hay otro en el libro, el llamado "La gran solución", cuyo escenario es también la ciudad de Asunción. Sin duda -y aunque menos "poético" que los demás-, este cuento es el mejor o uno de los mejores del libro.

El héroe $\longrightarrow$ mejor dicho-, el antihéroe de Roa, es el gerente de una ferretería asunceña. Roa nos pinta un hombre cuarentón, insignificante, débil de carácter, a quien, durante la guerra con Bolivia, el sólo pensamiento de ir al Chaco le produce sudores fríos. Al principio de la guerra nuestro hombre se siente seguro en su cómodo hogar, bien cuidado por una esposa cariñosa, la cual, no habiendo tenido hijos, ha concentrado todo su instinto maternal en su pusilánime compañero. Este se siente seguro, decíamos, porque su edad ha pasado en veinte años la requerida por el servicio militar. Pero acontece que el Chaco devora los contingentes jóvenes que van, unos tras otros, a las batallas. $Y$ ahora los hombres de treinta años, de treinta y un años, de treinta y dos, deben partir para el frente. $Y$ así, a medida que pasa el tiempo, nuevas clases son llamadas bajo banderas hasta que llega la hora en que los hombres de cuarenta años deben también marchar río arriba, hacia las selvas incendiadas por la metralla.

La esposa del antihéroe halla, entonces, la única solución posible: hacer que su marido sufra un "accidente" tras el cual sea declarado inepto para el servicio militar. Ella, con tino y diplomacia, recurre al repartidor de pan -un italiano socarrón, taimado, libidinoso-, el cual, conforme a un plan hábilmente ejecutado, hace su- 
frir al marido el salvador "accidente" y, en pago de este favor, exige y obtiene los de la esposa cómplice.

En este cuento espléndidamente logrado, sencillo y picante como uno de Boccaccio, digno por su ironía, de la pluma de Guy de Maupassant, Asunción no está descrita, aunque lo está, sin embargo, de un modo sutilmente indirecto. (A Asunción le pasa aquí -si se permite el paralelo- algo semejante a lo que a los caminos cervantinos de la Mancha, cuya imagen, no pintada sino sugerida genialmente por Cervantes, admiraba tanto a Flaubert). Nada falta y nada sobra en el relato. Los caracteres, dibujados con admirable finura, tienen vida propia y hablan un lenguaje que no puede ser sino el suyo. El desenlace no es, como el de otros cuentos de Roa, inverosímil, sino la natural consecuencia de los hechos.

Como cuento, como relato en sí, es lo más logrado del libro. $\mathrm{Y}$ adviértase que no son una consecuencia fortuita el éxito feliz del (uento y la ausencia total del afán redencionista que mueve al poeta en otras historias mucho menos perfectas, aunque, técnicamente más pretenciosas.

En "La gran solución", por otra parte, no se plantea tampoco un problema que el autor trató de resolver en otros cuentos en virtud de un arbitrio que, a mi juicio, resulta inadecuado. Me refiero al problema del idioma. Como se sabe, el Paraguay es un país bilingüe. En las ciudades se habla español y guaraní; en el campo prevalece el idioma aborígen, bien que ya muy desvirtuado por un número creciente de hispanismos.

Pues bien: en el cuento recién comentado los personajes hablan español y por tanto no hay problema. Estamos en la ciudad, con gente de la clase media. Pero cuando el escritor abandona la ciudad y va al campo, y cuando sus personajes deben expresarse en el idioma guaraní desvirtuado que hablan (el cual, aunque muy diferente del guaraní de hace cuatro siglos, es también muy distinto del español corriente), Roa pone en los labios de aquéllos una jerigonza que no es ninguna de las tres cosas. Es decir, sus personajes no hablan ni el guaraní de los guaraníes ni el guaraní de los paraguayos, ni el español que se habla en el Paraguay. El resultado es un feo pastiche que acaso pueda pasar por algo auténtico sólo para quien desconozca en absoluto la expresión oral del campesino paraguayo. $\mathrm{Y}$ es que el arbitrio de Roa consiste en hispanizar el 
guaraní al máximo y en guaranizar el español hasta donde le es posible, a fin de que los lectores no paraguayos puedan entenderle.

Yo creo que sería mejor, simplemente, traducir al español la lengua campesina $y$, con este necesario sacrificio de autenticidad evitar, con el pastiche, una falsificación antiestética del lenguaje de un pueblo.

\section{Técnica efectista y littérature engagée}

Hay un propósito inspirador, ya aludido, en el libro de Roa: la denuncia de la injusticia, de la tiranía, etc. Pues bien, el espectáculo de los males que abruman a un país que, según un geógrafo norteamericano, somehow missed being a Paradise, hace de Roa -cabe insistir aquí- un escritor violentísimo y le priva de la necesaria mesura.

En el más violento de sus relatos, el llamado "El trueno entre las hojas", los retratos de los sucesivos dueños de un ingenio de azúcar a orillas del Tebicuary, incurren, el primero, en un naturalismo obsceno y de malísimo gusto, y, el segundo, en inverosímil caricatura.

El primer dueño, un judío-español, Simón Bonaví, es el individuo más repulsivo que pueda imaginarse. Como prefiero no citar en estas cuartillas los párrafos intrascribibles en que se pinta la degradación moral del capitalista hispano-judío, refiero al lector a las páginas 199 y 201 del libro.

Roa ha querido hacer de Simón Bonavi un personaje ominoso, abominable, y lo ha logrado, pero a un precio demasiado subido: al precio del buen gusto, que supone la renuncia del arte verdadero. Hubiera podido hacer a su personaje profundamente odioso y repulsivo, sin necesidad de volcar sobre sus páginas esos manchones que las afean. (El retrato de Simón Bonaví, por lo obsceno, resulta comparable al de aquel "héroe" de Jean Paul Sartre del cuento "Erostrate".) 10

Este peligro del excesivo naturalismo - doy tal nombre a ese defecto por no hallar otro más adecuado-, es algo que Roa bien podría evitar para no incurrir en la falta deplorable de otros es- 
critores hispanoamericanos, especiamente algunos del Pacífico, cuyos efectos literarios resultan contraproducentes. Me refiero a los autores de ciertos libros en que se persigue la redención de las masas indígenas explotadas y miserables. Al terminar de leerlos, el lector no sabe qué le ha impresionado más penosamente: si las iniusticias denunciadas, o la suciedad que se rezuma a través de todos los poros de esas páginas impregnadas de dolorosa miseria... y de pésimo gusto.

La Doña Bárbara de Rómulo Gallegos acaba de celebrar el glorioso vigésimoquinto aniversario de su publicación al tiempo en que su autor celebraba, a su vez, en el destierro, el septuagésimo aniversario de su natalicio. ¿ $\mathrm{Ha}$ necesitado Gallegos recurrir a ese naturalismo excesivo para lograr los efectos propuestos? ¿Lo ha necesitado el autor de La vorágine? Ni Gallegos ni Rivera mojaron nunca su pluma en tinta que no fuera de buena ley, y sus obras, poéticas, puras, enérgicas, viriles, tienen hoy y tendrán mañana una fuerza y lozanía que jamás hubieran potenciado los antiestéticos recursos del mencionado naturalismo.

Pero dejemos estas digresiones y hablemos del segundo patrón que aparece en el cuento "El trueno entre las hojas". Este patrón ya no es español ni judío, sino norteamericano. (No es tampoco esta la primera vez que un villain angloamericano hace su violenta aparición en la literatura de nuestras tierras: basta recordar al Mr. Danger de Gallegos para citar a uno de los más conocidos.) Sin tmbargo, Harry Way, el villain que nos pinta Roa Bastos deja chiquitos a todos sus colegas literarios de ficción por su pasmosa ferocidad:

Entonces llegó Harry Way, el nuevo dueño. Llegó con dos pistolas colgándole del cinto, los largos brazos descolgados a lo largo de los "breeches" color kaki ( sic) y una agresiva y siniestra actitud empotrada sobre las cachas de cuerno de sus pistolas. Era grande y macizo y andaba a zancadas hamacándose como un ebrio. Sus botas rojas dejaban en la tierra los agujeros de sus zancajos. Los ojos no se le veían. Su rostro cuadrado, sobre el que echaba perpetuamente sombra el aludo sombrero, parecía acechar como una tronera de cemento la posible procedencia del ataque o elegir el sitio y calcular la trayectoria del balazo que él debía disparar... (P. 208.)

... A extremos increíbles llegó muy pronto la crueldad del Buey rojo, del Gũey-Pytá, como empezaron a llamar al fabriquero 
gringo Harry Way. Asi les sonaba su nombre. Y en realidad se asemejaba a un inmenso buey rojo. Sus botas, sus camisas a rayas coloradas, su pelo de herrumbre que parecía teñido de pensamiento sanguinario, su desbordante $\mathrm{y}$ sanguinaria animalidad... (pp. 211-212).

Iss probable que Hollywood jamás haya llevado a la pantalla un bandido tan atroz y cabal. Harry Way es un explotador de los miserables, que compra el ingenio azucarero no sólo porque éste es un negocio seguro, sino porque hay amenaza de huelga. $Y$ como esta amenaza de huelga le of rece la posibilidad de sofocar en sangre la aún no declarada rebelión de los obreros, tal posibilidad se le convierte en un incentivo poderoso para formalizar con Simón Bonaví el contrato de compraventa...

¿No es esto un poco excesivo? Harry Way, más que un personaje que pudo ser real, nos parece un villain de melodrama o un pirata o gangster de cuentos para niños.

Ahora bien, este villain espantable impone en el ingenio un régimen de terror aun mucho más cruel que el de su antecesor el judío español. Hasta que un día los obreros se sublevan, prenden fuego * la casa del monstruo y arrojan su cuerpo vivo a las llamas.

Debe aqui anotarse una incongruencia entre el principio del cuento y su desarrollo ulterior. Al fundarse el ingenio, el primer dueño, Simón Bonaví, agrupa a los obreros y los maneja y esclaviza como a un rebaño de borregos. Su capataz, un mulato feroz, gobierna a los antes libres campesinos a golpes de látigo y a pistoletazos. Un día muere el mulato asesinado. ¿Quién lo asesina? ¿Un obrero flagelado por el látigo esclavista, un padre deshonrado? ¡ No! Nada de eso. Lo asesina, nos cuenta Roa, la mujer lujuriosa del ingeniero alemán del establecimiento, no en venganza de desmanes bárbaros, sino por despecho amoroso. Los obreros, mientras tanto, siguen soportando la feroz tiranía sin una protesta, sin que ningún disparo salga de la selva $\mathbf{y}$ vengue tantas muertes $\mathrm{y}$ violaciones, tantos atropellos e iniquidades...

Los obreros, sí, odian la fabrica, odian a sus amos, odian su vida miserable. Son; sin duda, un rebaño de aterrorizados borregos. Hasta que llega por fin el día en que se sublevan, matan al gringo sanguinario y a sus capangas, y, entonces, se transforman como por milagro. Bajo la dirección de uno de sus líderes - que no es más 
que un peón como ellos, sin letras y sin experiencia técnica-, se organizan al día siguiente de la venganza y siguen trabajando en la fábrica para, con la venta del azucar, obtener la compensación económica que merecen por sus largos y mal pagados trabajos:

Formaron -dice Roa-, una comisión de administración en la que se incluyó a los técnicos. $\mathrm{Y}$ cada uno se alineó en lo suyo; los peones en la fábrica, los plantadores en los plantíos, los hacheros en el monte, los carreros en los carros, los cuadrilleros en los caminos... Se pusieron a trabajar noche y día sin descanso. Lo hacían con gusto, porque al fin sabían que el trabajo es una cosa buena y alegre cuando no lo mancha el miedo y el odio. El trabajo hecho en amistad y en camaradería. No pensaban, por otra parte, quedarse con el ingenio para siempre. Sabían que eso era imposible... (p. 220).

¡Claro que esto era imposible y que lo sería también bajo un régimen comunista, bajo la vigilancia de los Comisarios del Pueblo! ¿Se concibe una multitud de campesinos analfabetos, enfurecida hasta el paroxismo por una larga y terrible tiranía que, una vez saciada su sed de sangre y justa venganza, se ponga a trabajar ordenadamente $\epsilon n$ una fábrica, a cuyos dueños, aliados del poder público, acaban de linchar? Más verosímil sería que, en el furor de la venganza la multitud saqueara la fábrica, le prendiese fuego y, con el botín obtenido se dispersase.

Sin duda Roa no ha podido caer en la cuenta de ésta y de otras inverosimilitudes en quie incurre, porque la suya es, en gran parte, una littérature engagée.

E1 cuento "El caraguá" exhibe una técnica complicada. Todo el relato se reduce, sin embargo, al viaje que hace el relator al rancho de un colono, Sergio Miscowsky, el cual habita con algunos peones sordomudos a orillas de un fétido pantano o caraguá. El relator tiene por objeto ver con sus propios ojos a una supuesta hija incestuosa del colono que, según los pobladores del lugar más cercano, vive en horrible pecado con su propio padre.

Mientras el relator cabalga rumbo al pantano con el colono, la historia se desarrolla en virtud de una superposición de narraciones 
insertas en forma de flash-backs. Durante el viaje, por ejemplo, reaparece en la mente del relator la imagen de la posadera lugareña que le dió, además de albergue en su mugrienta posada, las primeras noticias del colono y de la misteriosa muchacha.

En este primer flash-back, la posadera destila en los oídos del selator toda la maledicencia del pueblo, y sólo se interrumpe, a meriudo para escupir contra la pared del mesón una bolita húmeđa ciel fuerte tabaco que masca. La descripción repetida de tan antihigiénica operación no satisface a Roa, quien, al parecer, se empeña en hacernos una pintura aún más realista de la mesonera, descrita ya como maligna, sucia y soez. Y en la página 123, en las líneas 14 y siguientes, nos cuenta, con lujo de detalles, una hazaña de incivilidad y grosería aún mayores de la chismosa, que prefiero no transcribir aquí.

¿Era necesario esto? ¿Es esto un adorno, un recurso para dar mayor realismo al cuento? No, en absoluto.

$\mathrm{El}$ áspero naturalismo del relato se inicia ya en la tercera línea del primer párrafo, cuando se nos dice que el caballo del colono Miscowsky tenía una "postema purulenta alrededor de la cual giraba zumbando una mosca verde casi tan grande como un tábano." (P. 113).

La alusión a la postema se repite al avanzar el relato.

Bien: que supure la postema y que gire y zumbe en torno a ella la mosca cuasi-tábano. Aquí, lo que se objeta, es otra cosa: en todo el cuento, lo accesorio, lo adjetivo - y lo antiestético- tienen un espacio y énfasis, en consideración a los cuales se sacrifica lo substancial. En efecto: la trama del cuento es interesante, muy interesante, tanto que su autor hubiera podido sacar gran partido de ella.

El lector se entera, hacia el final de la narración, que el colono Miscowsky es el fanático secuaz de una suerte de profeta y de bandido, ya muerto años atrás, el cual fuera promotor de un movimiento social-religioso y en tal carácter tuviera en jaque a la autoridad civil, hasta que un día, vencido en batalla campal por tropas del gobierno hallara su tumba en el pantano. La supuesta hija del colono resulta serlo del profeta-bandido y de una hermana de Miscowsky. Este último, que venera la memoria del profeta muerto, ha resuelto consagrar a la muchacha, esto es destinarla para siempre 
a una vida de soledad y castidad, y hacer de ella algo así como una vestal agreste.

Como se ve, la trama es interesante, pero resulta difusa en exceso porque se interrumpe con la continua introducción de pormenores e incidentes inesenciales. Los episodios, además, como ya se dijo, se van presentando por medio de los aludidos enfoques retrospectivos o flash-backs, en los que hablan la posadera, primero; un acopiador, después; luego Sergio Miscowsky, y, por fin, el relator mismo.

Roa hubiera simplificado la complejidad de su técnica; hubiera desdeñado esos pormenores naturalistas que en rigor afean la fluencia de su bella prosa, y se hubiera concentrado en un desarrollo más directo de su tema. Nos hubiera hablado más -y mejor- del profeta-bandido, $y$ menos de postemas, de espumarajos y otras lindezas por el estilo. El cuento carece de dinamismo y adolece de una cansada morosidad en descripciones adjetivas o de mal gusto.

Esta objeción nos lleva a plantear un problema general de técnica que Roa debiera resolver. Salvo en "Galopa en dos tiempos", en "La gran solución" y en alguno que otro relato, la narración en sí es algo secundario en el escritor de El trueno entre las hojas. Muchos autores asumen una actitud semejante en cuanto a la creación artística del cuento. Pero Roa no logra los resultados que podrían esperarse de su gran talento al hacer hincapié más en las emociones de sus héroes $\rightarrow$ en otras cosas menos espirituales-, que en lo que les ocurre en el mundo exterior en que coexisten con los seres y las cosas.

Rara vez puede Roa compensar, con primores de estilo o sutile- zas psicológicas la falta de una estructura dinámica que se echa de menos en sus relatos. De aquí que cuando alguno de éstos tiene un argumento bien tramado y desarrollado, el poeta logre un efecto muy superior al que logra en otras historias donde lo adjetivo pugra en vano por substancializarse con bella poesia lírica o con disquisiciones psicológicas.

Acaso todos estos reparos puedan reducirse a uno solo: el escritor Roa tiene una indebida preocupación por el efecto que ha de producir en el lector. Su literatura, pues, según esta hipótesis, tiende al efectismo. De aquí que emplee esos ingredientes chocantes del viejo naturalismo - aunque modernizados a fuerza de mayor 
rudeza-, y de aquí también que cargue el acento sobre to accesorio, ya subrayando pormenores inesenciales, ya elaborando bellos trozos líricos de primoroso estilo cuando la sazón no lo requiere.

Claro es que esto no sucede siempre. En su hermoso cuento "El viejo señor obispo" Roa nos relata la vida, pasión y muerte de un prelado ejemplar que nunca ha transigido con las corruptelas del poder civil ni con el espíritu mundano y acomodaticio de sus superiores eclesiásticos.

E1 viejo señor obispo vive franciscanamente con una hermana piadosa y humilde, la solterona señorita Teresa. Vive en una casa pobrísima, cuyos muebles se van vendiendo unos tras otros, hasta que la casa queda desmantelada. Todo lo que tienen los dos hermanos lo distribuyen entre los menesterosos.

En la primera parte del cuento, el obispo hace una vida activa, asume una actitud militante y rebelde. Es el relato de su juventud. En la segunda parte, se enfoca la vida del prelado en su ancianidad, poco antes de morir. La descripción de la casa del santo varón es admirable. Admirables también son los retratos de los once mendigos que a diario se sientan en torno a su mesa. Son estos como los mendigos de Valle-Inclán en Romance de Lobos y en Divinas palabras. La técnica pictórica es similar $\mathrm{y}$, no obstante, estamos, al leer el cuento, en Asunción, y dentro de Asunción, en el barrio de la Recoleta.

El estilo de Roa asume su máxima belleza. La estructura del relato es compleja, pero de una complejidad diáfana. Enfoques del pasado y del presente se combinan diestramente para ampliar la perspectiva.

Desde el comienzo del relato se anuncia la enfermedad del obispo: la vieja solterona atisba la habitación donde reposa su hermano. Es hora ya de levantarse, pero el obispo, contra su costumbre, sigue tendido en su ascética yacija ... La situación está descrita de mano maestra: hay una ansiedad contenida en la pobre beata, ansiedad que Roa logra transmitirnos en pocas palabras esenciales:

- ¿Cómo se siente, Pai? - preguntó en la puerta con un hilillo de voz. Al no tener respuesta, insistió: - ¿ No necesita nada, monseñor? ¿Un té de verbena y zarzaparrilla bien caliente? 
Esta escena se prolonga por unos instantes. (Porque, en verdad, la introducción del cuento constituye una verdadera escena). Crece la ansiedad de la beata, a la que vemos juntar las manos y oprimírselas dolorosamente, mientras en su faz cansada y triste la preocupación ahonda las arrugas de su casta vejez; escuchamos el ruido asordinado de sus pasos, adivinamos que se afana en tender la mesa y hacer los últimos preparativos de la cena, no sólo porque los mendigos van a llegar de un momento a otro, sino porque quiere distraerse, aturdirse, olvidar sus temores....

Afuera, en la noche, ulula el viento invernal.

La escena termina y con ella la narración en tiempo presente. $Y$ comienza el relato de la juventud del prelado. Luego, acabada esta evocación de antiguos hechos, el escritor nos conduce otra vez a la casa actual del obispo enfermo y de su hermana. $\mathrm{Y}$ entonces aparecen los mendigos, uno tras otro, en sucesión de retratos valleinclanescos, reminiscentes, también, de la técnica descriptiva de Gabriel Miró. $\mathrm{X}$ con relieve trágico, vacilando bajo el peso de su enorme infortunio avanzan hacia el lector estas criaturas horribles, monstruosas, carcomidas por la lepra de la miseria.

Todo el cuento parece tener el propósito de decirnos cómo se premia la verdadera virtud y la santidad en una tierra a la que sacude la violencia del trueno.

$\mathrm{El}$ obispo muere aquella misma noche invernal. $\mathrm{Y}$ no, hay dinero para comprar un ataúd. En vano la hermana beata acude, a la mañana siguiente a la Curia metropolitana. La Curia promete honras fúnebres con toda la pompa ritual, pero se niega a comprar el ataúd.

Esto último, que resulta poco verosímil está, sin embargo, admirablemente dicho. La señorita Teresa no tiene ahora a nadie a quien recurrir, con excepción de los ... mendigos. $\mathrm{Y}$ son los mendigos quienes van a sacar a la hermana del difunto obispo de este trágico apuro. Ellos venden el viejo armonio, único mueble de algún valor que quedaba en la casa del prelado, y con su precio, compran la caja fúnebre.

El entierro del obispo está descrito con patetismo conmovedor. Aquí Roa pinta algunos pormenores con tan buen tino que cada uno de ellos asume una nota de esencialidad proyectada sobre el conjunto del cuadro. 
Hay en el cuento párrafos de bellísima prosa, tales como uno en que se nos relata la angustia de la señorita Teresa frente al cadáver insepulto de su hermano. No sabiendo qué hacer en su desvalida soledad, la anciana sale a la calle en busca del ataúd:

La señorita Teresa se echó sobre la cabeza el manto negro y salió a la calle. Tenía que conseguir un ataúd para su hermano. No pensaba en honras fúnebres, en los paramentos violetas y dorados de la liturgia romana, en grandes y sonoros responsos, en solemnes comitivas, en discursos, en carrozas y caballos de un negro resplandeciente portando innumerables coronas. Su hermano necesitaba ahora mucho menos que eso. Sólo las cuatro tablas lisas para su cuerpo pudiera dormir en paz bajo la tierra oscura. Su alma ya estaba fundida en la luz, en el canto de los pájaros, en la celeste calma del universo como una gota del fuego de Dios - pensó ella-, disuelta en un infinito cántaro de oro... (p. 38).

Este espléndido vuelo de la fantasía es como un géyser luminoso que se yergue de súbito de entre eșas páginas sombrias de luto $\mathrm{y}$ desamparo. $Y$ es una glorificación de lo espiritual en contraste directo con el fondo de la patética miseria física y moral de los mendigos, a los que ahora ilumina la santidad del obispo difunto con el fulgor de un maravilloso amanecer.

\section{6}

\section{Los carpincheros}

Como poeta de verdad, Roa Bastos es un creador de mitos. $E l$ trueno entre las hojas, libro en que el Paraguay aparece como un país de opresión y de miseria, y donde sólo hallamos, de vez en vez, la historia de alguno que otro héroe oscuro y trágico, fulminado por un destino cruel e implacable, hace lugar aparte para una raza de hombres libres, fuertes, puros, que no viven sobre la tierra terrible que sacude el trueno, sino sobre las aguas verdes de un río caudaloso.

Son estos hombres los cazadores de carpinchos, atletas de broncinea estampa, que, de pie en sus primitivas canoas, se deslizan rápidos sobre la corriente del Tebicuary. Los carpincheros — que así se llaman-, son seres humanos sin otra ley que su fuerza hercúlea y un innato sentido de justicia. En el primero y en el último cuento de 
El trueno entre las hojas, aparecen como visiones mitológicas. Surgen de entre las tinieblas de la noche de San Juan, como fantasmas fluviales, al resplandor de hogueras que flotan entre camalotes. $Y$ surgen como los dioses de las tragedias antiguas, para intervenir con su poder superior en los afanes y miserias de los simples mortales.

Así como el Lorca que fascinó la juventud de Roa hiciera de los gitanos un tema poético enormemente sugestivo, Roa hace de los carpincheros criaturas de mítica poesía, seres semifabulosos, incontaminados, magnánimos, exentos de la maldición de la leyenda aborigen. "Son - dice Roa-, los vagabundos del río, los gitanos del agua...", (p. 12).

\section{7}

\section{Conclusión}

Si tuviera yo que resumir en pocas palabras las cualidades y defectos de El trueno entre las hojas - ya que el espacio disponible no permite el análisis detenido que cada uno de sus cuentos merece-, diría lo siguiente :

El libro está muy bien escrito, tiene un patetismo a veces conmovedor, que emerge de un sentimiento genuino y generoso. El libro, también, es obra de poeta, esto es, exhibe las calidades que le infundió un espiritu egregiamente lírico.

Sus defectos ya han sido anotados. Mas, como el propósito que anima a este artículo es el de una crítica constructiva que apunta más que a éste, a los libros futuros del escritor paraguayo, quiero insistir sobre algunos puntos.

En primer lugar, Roa no debiera subordinar su arte a una finalidad no artística. Debe, ante todo, concebir su obra como obra de arte. Primero el arte. Lo demás vendrá a su obra por añadidura, y en forma mucho más convincente. Por otro lado, si siente él la urgencia imperiosa de dar voz a su afán redencionista ¿ por qué no emplea otro medio de expresión, distinto del cuento? Roa podría ser un brillante ensayista. En su lúcida prosa, y a la luz de una teoría estricta, él podría hacer un análisis riguroso de los males de su patria y formular un programa positivo de regeneración. 
De este modo no sólo contribuiría directamente a la solución de los problemas que le afligen, sino que podría dar al cuento lo que es del cuento y al ensayo lo que es del ensayo.

Roa también debe evitar la exageración. La verdad basta; ya tiene ella en sí y por sí una elocuencia que no necesita distorsiones. Tampoco debe recurrir a los efectismos de esa literatura que un crítico sueco ha llamado de flottiga papperet, "de papel grasiento".

Y para terminar diré que en los próximos libros del prosador paraguayo sería deseable ver al Paraguay tal como es, con lo malo y con lo bueno. Más aún, quisiera el lector gozar de una interpretación artística del paisaje, de la tierra y del hombre en su dramático diálogo. Porque mientras Roa no nos ofrezca una visión así, completa y cabal, todos sus elevados afanes de justicia y redención social, resultarán un poco a-tópicos y un poco a-crónicos. Esto es, sin esa adscripción concreta a un lugar determinado del espacio y del tiempo.

Hugo Rodríguez-Alcalá. The State College of Washington.

\section{$\mathrm{NOTAS}$}

1 Augusto Antonio Roa Bastos nació en Asunción en 1918. Asistió, durante algún tiempo al Colegio San José, uno de los mejores de esa ciudad. Publicó su primer libro de versos: El ruiseñor de la aurora y otros poemas en 1940. Al año siguiente presentó una novela: Fulgencio Miranda, al concurso organizado por El Ateneo, la cual recibió mención honorífica. Es autor de varios dramas, como La Residenta, El niño del rocio, y de otro, representado sin éxito en 1946, cuyo argumento se desarrolla en la Alemania nazi. Roa Bastos ha trabajado varios años en la redacción de El País, de Asunción y ha viajado mucho por América y Europa.

En 1953 publicó su último libro, El trueno entre las hojas, en la Editorial Losada, S. A., de Buenos Aires.

2 De la "Epístola a un poeta de estilo arcaico", del autor de este artículo y reproducida por el mismo Roa en El Pais, de Asunción, el 3 de septiembre de 1938.

3 "Contestando a una epístola", El Pais, 3 de septiembre de 1938.

4 Sinforiano Buzó-Gómez, Indice de la poesía paraguaya, (Buenos Aires: Editorial Tupá, 1943), p. 363. 
5 Ibid., p. 373.

6 Ibid., pp. 372-373.

7 Véase Walter Wey, La poesia paraguaya: historia de una incógnita, (Montevideo: Biblioteca Alfar, 1951). Para un estudio de la poética y poesía de Hérib Campos Cervera, ver mi ensayo "Campos Cervera, poeta de la muerte", en Revista Iberoamericana, vol. 17, núm. 33, año 1952.

8 Ver Augusto Roa Bastos, El trueno entre las hojas, (Buenos Aires: Editorial Losada, S. A., 1953), p. 9.

9 Véase mi artículo "Julio Correa visto por sí mismo", Revista Iberoamericana, volumen 15, núm. 30, 1951.

10 Ver Le mur, Paris, Gallimard, 1939. 
